SISTEMA
ELETRÔNICO
DE REVISTAS
SER I UFPR

\title{
Dos conflitos ambientais à ética socioambiental: um olhar a partir dos povos e comunidades tradicionais
}

\section{From environmental conflicts to socio-environmental ethics: an approach from the traditional communities' perspective}

\author{
Luciano Félix FLORIT ${ }^{1 *}$ \\ ${ }^{1}$ Programa de Pós-Graduação em Desenvolvimento Regional, Universidade Regional de Blumenau (FURB), Blumenau, SC, Brasil. \\ *E-mail de contato: lucianoflorit@gmail.com
}

Artigo recebido em 29 de maio de 2018, versão final aceita em 11 de novembro de 2019.

RESUMO:

Este trabalho discute inter-relações entre ética ambiental e a reflexão crítica sobre os padrões de desenvolvimento. Tem como foco a análise dos conflitos entre sistemas de valores que subjazem aos conflitos ambientais e aos processos de territorialização que afetam comunidades tradicionais. A ética socioambiental referida no título é entendida nesse contexto como o campo de reflexão que faz uma interface entre a ética ambiental e os estudos sociais das iniquidades ambientais. No artigo, busca-se evidenciar as relações entre ética socioambiental e a perspectiva dos povos tradicionais que enfrentam esse tipo de conflitos. Esta conexão é examinada através da análise de duas entrevistas a porta vozes de povos tradicionais. Destaca-se o significado emancipador das lutas territoriais desses povos na defesa do seu lugar, como um fenômeno que afirma uma contestação da redução instrumental da natureza imposta pelas cadeias de produção integradas à lógica global e à territorialidade urbano-industrial-capitalista.

Palavras-chave: ética socioambiental; conflitos de valoração; conflitos territoriais; não humanos; desenvolvimento.

ABSTRACT: This paper discusses some interrelationships between environmental ethics and critical reflection on development patterns. It focuses on the analysis of conflicts between value systems that underlie environmental conflicts and the processes of territorialization that affect traditional communities. The socio-environmental ethics referred is understood, in this context, as the field of interfaces between environmental ethics and social studies of environmental inequities. In the article, it is tried to evidence the relations between socio environmental ethics and the perspective of traditional people that face this type of conflicts. This connection is examined through the analysis of two interviews with spokespeople of traditional peoples. The article highlights the emancipatory 
meaning of the territorial struggles of these peoples in defense of their place. It is considered as an affirmative contestation of the instrumental reduction of nature imposed by the production chains integrated to the global capitalist logic and the urban-industrial-territoriality.

Keywords: socio-environmental ethics; valuation conflicts; territorial conflicts; non-human; development.

\section{Introdução}

Embora a ética ambiental, em seus aspectos filosóficos, seja uma subdisciplina bem definida (Callicot, 2001; Singer, 2002; Elliot, 2004; Taylor, 2011; Felipe, 2012) $)^{1}$, suas interfaces com os estudos sociais das iniquidades ambientais ainda requerem formulações teóricas e pesquisa empírica, especialmente no sentido das ciências sociais realizarem análises críticas da produção social do tratamento meramente instrumental de não humanos, e de superar os limites antropocêntricos que costumam permear os estudos sociais ${ }^{2}$.

Este trabalho discute inter-relações entre ética ambiental e a reflexão crítica sobre os padrões de desenvolvimento. Tem como foco a análise dos conflitos entre sistemas de valores que subjazem aos conflitos ambientais e aos processos de territorialização que afetam comunidades tradicionais, dando realce e analisando suas valorações da natureza ${ }^{3}$.
A ética socioambiental referida no título é entendida aqui como o campo de reflexão que faz uma interface entre a ética ambiental e os estudos sociais das iniquidades ambientais. No plano analítico, implica estudar as relações sociais que resultam na desconsideração moral da natureza e dos seres vivos não humanos, o que, no contexto contemporâneo, tendemos a chamar de coisificação ou objetificação. No plano normativo, implica em conciliar a consideração moral desses seres vivos com a afirmação da justiça ambiental entre seres humanos.

Nesse texto, me aproprio de alguns trabalhos realizados no contexto do Grupo de Estudos sobre Temáticas Ambientais (GESTA-UFMG) nos últimos anos e explicito conexões analíticas direcionadas à problemática enunciada. Também busco evidenciar as relações entre essas conexões analíticas e perspectivas de povos tradicionais a partir de duas entrevistas. Desse modo, ao longo do texto, vou explicitando conceituações que

\footnotetext{
${ }^{1} \mathrm{O}$ que não significa que não seja um campo com diversas correntes e controvérsias. Numa excelente introdução à área, Elliot (2004) classifica as éticas ambientais de quatro maneiras: 1) centrada no ser humano; 2) centrada nos animais; 3) centrada na vida; e 4) ética do todo ou ética do holismo ecológico. Pessoalmente, entendo que a potencialidade reflexiva dessa área para as discussões relacionadas aos aspectos éticos e políticos do desenvolvimento é mais bem exprimida se estabelecermos uma distinção entre as correntes holistas e individualistas da ética ambiental (Callicot, 2001; Varner, 2001; Florit, 2016).

${ }^{2}$ Trata-se de uma empreitada que já foi iniciada por autores como Leonardo Boff (1938 - ), Héctor Ricardo Leis (1943 - 2014), Enrique Leff (1946 - ), Eduardo Gudynas (1960 - ), e Paulo Henrique Freire Vieira que, embora com ênfases diferentes, discutem com disposição interdisciplinar os desafios ético-políticos do ambientalismo incluindo a crítica da racionalidade instrumental que prevalece com a natureza e os seres humanos.

${ }^{3}$ Trata-se de uma reflexão iniciada no contexto do estágio pós-doutoral realizado no GESTA (Grupo de Estudos sobre Temáticas Ambientais) da Universidade Federal de Minas Gerais (UFMG), em 2016, e continuada no contexto do Grupo IPÊS (Grupo Interdisciplinar em Pesquisas Socioambientais) da FURB. O projeto contou com o apoio do CNPq através de bolsa PDS (Pós-Doutorado Sênior), $\mathrm{n}^{\circ}$ do processo 157897/2015-0.
} 
considero cruciais de uma ética socioambiental tal como definida acima - o campo de interface entre a ética ambiental e os estudos sociais das iniquidades ambientais.

Na seção que segue a esta Introdução, detenho-me na conceituação dos conflitos ambientais territoriais e na perspectiva que permite vê-los também como conflitos de valoração. Isto evidencia, penso, que as valorações da natureza conflitantes nos processos de imposição de padrões de "desenvolvimento" têm uma dimensão territorial que é fundamental. Na sequência, exploro a conceituação de povos e comunidades tradicionais enfatizando o papel da relação direta com a natureza no contexto da realização de necessidades vitais e a diversidade de valorações, não apenas instrumentais, mobilizadas nesses processos. Destaco aqui o significado emancipador das lutas territoriais destes povos na defesa do seu lugar, como um fenômeno que afirma uma contestação da redução instrumental da natureza imposta pelas cadeias de produção integradas à lógica global e à territorialidade urbano-industrial-capitalista. Também mostro que nessas lutas territoriais estão presentes formas não dualistas, sintéticas e altamente elaboradas de valoração da natureza, que merecem ser levadas a sério como contribuição ética. Na terceira seção, busco explorar algumas implicações da virada ontológica na antropologia da natureza e na antropologia do desenvolvimento. Faço isto tentando mostrar que a "multiplicidade de mundos", a que se refere Escobar, implica, também, em questionamentos substantivos da valoração da natureza meramente instrumental do capitalismo globalizado. Finalmente, trago as falas de dois sujeitos a quem considero aqui como porta-vozes de povos tradicionais, produto de entrevistas, em um caso, realizada por mim, e em outro, publicada num jornal online. Através da análise dessas falas, tento verificar a correspondência entre o olhar dos povos tradicionais e as reflexões teóricas realizadas nas seções anteriores. Nelas identifico elementos relevantes para uma ética socioambiental, como as formas de valoração não limitadas pelo dualismo valor moral/valor instrumental, a situalidade territorial, e o critério de suficiência como limite moral.

Para a discussão específica aqui proposta, requer-se que assumamos definições que façam distinções entre a reflexão ética e a dinâmica das moralidades. Essas distinções precisam ser feitas com cuidado, justamente pelos "sentidos diferenciados" e "ambiguidades" que estes termos observam não apenas no senso comum, mas também entre especialistas (Pedro, 2014). Por outro lado, esse zelo remete ao cuidado que devemos ter por estarmos tratando de um espaço interdisciplinar entre a reflexão filosófica (Rachels \& Rachels, 2013) e os processos sociais de produção e reprodução de valores que são apreendidos através das ciências sociais (Hitlin, 2015). Portanto, as definições a seguir não surgem de uma exegese conceitual, que seria pouco oportuna aqui, mas da necessidade operacional de convencionar uma linguagem adequada para a discussão proposta.

Entendo por moralidades (no plural), os valores dominantes em grupos ou sociedades, que tendem a ser repassados de geração a geração de forma indissociável da reprodução de valores culturais, religiosos e das práticas sociais rotineiras. As moralidades ambientais, portanto, consistiriam nos valores a partir dos quais grupos humanos se relacionam com a natureza e os seres vivos não humanos no contexto de sua reprodução material e cultural, que aparecem expressos nas suas práticas sociais e na sua territorialidade. Já a ética, como 
entendida aqui, é a reflexão sistemática sobre esses valores morais, realizada com o intuito de se chegar a uma conclusão sobre se esses critérios de valor devem ser considerados corretos ou incorretos. A ética ambiental é, assim, o campo de reflexão crítica sobre os valores por meio dos quais estabelecemos as relações com a natureza e os seres vivos não humanos. Assim, enquanto a reflexão ética é uma atividade que tem um tensionamento filosófico, a reprodução de valores no contexto das moralidades é um fenômeno social, inteligível pela análise sociológica, antropológica e política. Embora se trate de aspectos que na vida social se relacionam influenciando-se reciprocamente, é importante perceber que remetem a domínios diferentes (Pedro, 2014). A ética socioambiental, como foi definida no início do trabalho, seria o campo de reflexão que faz uma interface entre a ética ambiental e os estudos sociais das iniquidades ambientais, preocupada, normativamente, com a conciliação entre a consideração moral de seres vivos não humanos e a afirmação da justiça ambiental entre humanos.

Este artigo se insere nesse contexto de reflexão, procurando somar e contribuir com os esforços individuais e coletivos dos últimos anos ${ }^{4}$, argumentando que os povos e comunidades tradicionais devem ser vistos como sujeitos fundamentais da construção dessa ética socioambiental.

\section{Conflitos ambientais territoriais $e$ conflitos de valoração}

Os estudos de conflitos ambientais decorrentes de grandes projetos que afetam populações tradicio- nais mostram a existência de múltiplas valorações da natureza em confronto com a racionalidade hegemônica do capitalismo globalizado e, ao mesmo tempo, evidenciam que este confronto se expressa através da dimensão territorial. Klemens Laschefski analisa esse tipo de confronto, colocando em foco o problema da iniquidade inerente aos processos de licenciamento ambiental que não levam em consideração as concepções do ambiente das populações atingidas. Nos casos estudados, as populações são justamente grupos sociais que mantêm formas de uso da natureza muito distantes dos usos "monoculturais" típicos do modelo de desenvolvimento dominante (Laschefski, 2011).

Por exemplo, as populações atingidas por barragens no Vale do Jequitinhonha (MG), assim como na maioria dos casos em que os grandes empreendimentos afetam áreas rurais, são comunidades tradicionais, pluriativas, com produção agrícola e artesanal, apenas parcialmente integradas ao mercado. Especificamente nesse caso, trata-se principalmente de comunidades ribeirinhas com forte identidade com o local, ao qual se associam formas específicas de uso do território e seus recursos naturais. Tais usos são em grande medida ajustados aos ciclos e ritmos naturais, regulados por regras comunitárias que são específicas para cada tipo de recurso, resultando num modo de produção do espaço altamente entrelaçado com a natureza. Essas regras resultam também em códigos morais, reproduzidos através das suas relações de parentesco e vizinhança que configuram uma organização social particular (Laschefski, 2011).

Esse modo de vida vem sendo totalmente hostilizado e ameaçado por outra racionalidade de

${ }^{4}$ Florit, 2016, 2017; Florit \& Grava, 2016; Florit, Sbardelati \& Grava, 2019; Florit, Sampaio \& Philippi, 2019 ; Marzochi, 2018. 
construção do espaço, decorrente da territorialidade urbano-industrial-capitalista que passou a considerar o Vale do Jequitinhonha como "uma região destinada a fornecer matéria-prima, alimentos e energia necessários para a reprodução dos centros urbanos emergentes" (Laschefski, 2011, p. 32).

Esta região, objeto de grandes projetos hidroelétricos ${ }^{5}$, também passou por um embate simbólico. Neste, a despeito da existência de comunidades com qualidade de vida em geral superior à de trabalhadores assalariados nas indústrias, nas fazendas e nos empreendimentos florestais, passou a ser visto como "vale da miséria". Este rótulo, foi atribuído à região pelos atores responsáveis pelos empreendimentos, tendo como referência os dados econômicos característicos do ciclo decadente da mineração industrial, que não refletem a economia regional e local, nem expressam as condições de vida das comunidades tradicionais (Laschefski, 2011).

Segundo Laschefski (2011), os conflitos ambientais são resultado da expansão do espaço ambiental de grupos privilegiados, e podem ser classificados em três tipos: espaciais, distributivos e territoriais. Os conflitos espaciais acontecem nos casos de poluição (sonora, gasosa, hídrica ou de resíduos sólidos) que afetam a qualidade de vida da população que recebe a poluição. Estes, em alguns casos, podem ser resolvidos através de meios técnicos (filtros, por exemplo) na medida em que consigam limitar ao território do próprio gerador o impacto da poluição. Os conflitos ambientais distributivos são os que revelam assimetrias nos benefícios decorrentes da apropriação e uso dos recursos e serviços ambientais. A esses não cabe uma solução técnica, mas um tratamento por meio de perspectivas ambientalizadas de economia política (sejam essas clássicas, neoclássicas, neoliberais, marxistas ou keynesianas) ou da ecologia política ${ }^{6}$. Já nos conflitos ambientais territoriais, o que está em jogo é a sobreposição da territorialidade de grupos mais poderosos em territórios de grupos subalternizados, como no caso da remoção de atingidos sem que seja oferecida condições de reproduzir suas relações socioambientais. Nesse tipo de conflitos,

[...] as territorialidades de grupos sociais, ou seja, os modos diferenciados de apropriação simbólica e material do meio ambiente, envolvem justamente modos distintos de ver o mundo ou de 'produzir' o espaço que, quando materializados no espaço concreto, se revelam incompatíveis (Laschefski, 2011, p. 29).

Trata-se, portanto, do resultado de relações desiguais de poder entre aqueles que promovem o modo urbano-industrial-capitalista de produção do espaço e as comunidades locais. Estes conflitos territoriais evidenciam as territorialidades dos grupos contrapostos as quais envolvem também valorações da natureza contrapostas. No caso da territorialidade das comunidades tradicionais, essas valorações permitem lógicas de uso específicas, diversas da lógica capitalista, não redutíveis à mera coisificação/objetificação.

Para Martínez-Alier (2007, p. 353), “existe um choque de sistemas de valoração quando os dis-

\footnotetext{
${ }^{5}$ A análise realizada por Laschefski toma como exemplos os casos das barragens de Irapé e Murta.

${ }^{6}$ Laschefski (2011) não inclui explicitamente nesta relação a ecologia política. Optamos por incluí-la, assumindo a definição de Martínez-Alier (2007) que entende a ecologia política como a subdisciplina que analisa fundamentalmente conflitos ecológicos distributivos. Contudo, a ecologia política também pode ser vista como uma abordagem abrangente que inclui os diversos tipos de conflitos ambientais territoriais e de valoração, o que justifica a não menção explícita por parte do autor.
} 
cursos da justiça ambiental, dos direitos territoriais indígenas ou da segurança ambiental se desdobram em oposição à valoração monetária dos riscos e das cargas ambientais". Contudo, esses conflitos de valoração não são apenas monetários, nem sequer apenas econômicos. Eles dizem respeito, sobretudo, à apreciação do aspecto do real ao que é conferido maior relevância em função de um olhar ancorado numa posição de interesse. Como afirmam Funtowicz \& Ravetz (1994 apud Martínez-Alier, 2007, p. 354),

[...] o valor monetário será observado como a medida de um só aspecto de valor que reflete um tipo particular de interesse, aquele que encontra expressão principalmente por intermédio do mercado comercial. Escolher uma definição operacional particular de valor implica tomar uma decisão a respeito do que é real e importante; outras definições refletirão as crenças e interesses de outros atores... Isso implica uma pluralidade de perspectivas e valores.

Reconhecer essa pluralidade, como tenho afirmado em outro lugar, é uma condição sine qua non de justiça ambiental em conflitos que envolvem povos e comunidades tradicionais (Florit, 2016).

Assim, a produção do espaço desses grupos, embora contenha uma valoração de uso da natureza na medida em que (tais grupos) dependem do uso direto dessa para atender suas necessidades vitais, implica numa combinação complexa de valorações, não apenas instrumentais, que adicionam uma carga de sentido e significação simbólica que é indissociável do uso para o provimento material. Reconhecer essa complexidade de sentidos e valorações ajuda a entender porque há algo que esses povos defendem, que não é substituível através de operações monetizadas, que embora esteja conectado com seu suprimento material não se reduz a ele. Isso indica que a sua defesa da natureza, do rio, da mata e dos animais não é apenas a defesa de um ambiente produtivo, mas a defesa de algo ao que se reconhece consideração moral.

\section{Povos e comunidades tradicionais, natureza e território}

Para adentrar na conceituação da categoria Povos e Comunidades Tradicionais convém começar por um breve relato do percurso que levou à sua formulação. Trata-se de um percurso ao mesmo tempo analítico, político e jurídico que combina os efeitos de demandas sociais consagradas na Constituição de 1988 com discussões surgidas no contexto do debate ambiental, com conhecimento etnográfico produzido no Brasil nas últimas três décadas. $\mathrm{O}$ intuito aqui não é examinar as implicações jurídicas e no campo dos direitos desses povos e comunidades, nem fazer uma exegese exaustiva da trajetória do conceito, mas identificar os aspectos conceituais mais fortemente associados com o modo com que esses grupos se relacionam com a natureza, a paisagem e os seres vivos não humanos.

Aderval Costa Filho apresenta o decurso do conceito (Costa Filho, 2010). Para o autor, a categoria "povos ou comunidades tradicionais" é produto relativamente novo da interação de esferas governamentais, acadêmicas e sociais. Ele enfatiza que a expressão "comunidades ou populações tradicionais" foi utilizada para regulamentar o Artigo 225 da Constituição Federal 
através da Lei 9.985, de 18 de julho de $2000^{7}$. Portanto, para o autor, a questão adquire esse formato pela construção realizada no contexto da criação de unidades de conservação com o intuito de encontrar solução aos conflitos decorrentes da implantação das mesmas e as comunidades tradicionalmente residentes nestas áreas. Estas comunidades são não apenas indígenas e quilombolas, mas também agroextrativistas, pescadores, ribeirinhos, etc. (Costa Filho, 2010).

Posteriormente, entre 2004 e 2007, ocorreram iniciativas governamentais que resultaram na formulação da Política Nacional de Desenvolvimento Sustentável dos Povos e Comunidades Tradicionais. A mesma teve como característica marcante a ampla participação da sociedade civil, e foi instituída através do Decreto 6.040 de 7 de fevereiro de $2007^{8}$. Esse decreto, no seu artigo $3^{\circ}$, fornece algumas definições operacionais:

i - Povos e Comunidades Tradicionais: grupos culturalmente diferenciados e que se reconhecem como tais, que possuem formas próprias de organização social, que ocupam e usam territórios e recursos naturais como condição para sua reprodução cultural, social, religiosa, ancestral e econômica, utilizando conhecimentos, inovações e práticas gerados e transmitidos pela tradição;

ii - Territórios Tradicionais: os espaços necessários a reprodução cultural, social e econômica dos povos e comunidades tradicionais, sejam eles utilizados de forma permanente ou temporária, observado, no que diz respeito aos povos indígenas e quilombolas, respectivamente, o que dispõem os arts. 231 da Constituição e 68 do Ato das Disposições Constitucionais Transitórias e demais regulamentações; e

iii - Desenvolvimento Sustentável: o uso equilibrado dos recursos naturais, voltado para a melhoria da qualidade de vida da presente geração, garantindo as mesmas possibilidades para as gerações futuras (Brasil, 2007).

Essa definição expressa vários elementos analíticos importantes, alguns dos quais quero destacar aqui. Eles fazem referência explícita à dependência do uso direto da natureza para a realização das necessidades materiais e culturais desses povos, a qual acontece em territórios específicos ocupados tradicionalmente através de usos diversos, que seguem regras coletivas próprias, e que expressam uma continuidade transgeracional.

A sociabilidade destes grupos é intrinsecamente vinculada ao uso direto da natureza para sua reprodução. Para Diegues (1996, p. 87 apud Costa Filho, 2010, p. 2),

comunidades tradicionais estão relacionadas com um tipo de organização econômica e social com reduzida acumulação de capital, não usando força de trabalho assalariado. Nelas, produtores independentes estão envolvidos em atividades econômicas de pequena escala, como agricultura e pesca, coleta e artesanato. Economicamente, portanto, essas comunidades se baseiam no uso dos recursos naturais renováveis [...]. Seus padrões de consumo, baixa densidade po-

\footnotetext{
${ }^{7}$ A Lei no. 9.985, de 18 de julho de 2000, regulamenta o Art. 225 da Constituição Federal e também institui o Sistema Nacional de Unidades de Conservação da Natureza. Essa lei menciona explicitamente as denominadas "populações tradicionais" (Art. 17) ou "populações extrativistas tradicionais" (Art. 18) e focaliza a relação entre elas e as unidades de conservação (área de proteção ambiental, floresta nacional, reserva extrativista, reserva de desenvolvimento sustentável). Não obstante, a lei não fornece uma definição sobre o que seriam as "populações tradicionais" (Costa Filho, 2010, p. 2).

${ }^{8}$ Os documentos jurídicos, nacionais e internacionais, que foram decisivos para a definição de Povos e Comunidades Tradicionais, podem ser encontrados em versão completa em: Shiraishi Neto, J. (org.) 2007.
} 
pulacional e limitado desenvolvimento tecnológico fazem com que sua interferência no meio ambiente seja pequena...

Essas características implicam numa territorialidade específica, que frequentemente é confrontada e ameaçada pela territorialidade urbano-industrial-capitalista, conforme explicado acima, de outros grupos sociais ou mesmo do Estado Nação.

A territorialidade é também um aspecto destacado por Costa Filho, que remete a Little, para quem a mesma se traduz em características como

a existência de regimes de propriedade comum, o sentido de pertencimento a um lugar, a procura de autonomia cultural e práticas adaptativas sustentáveis que os variados grupos sociais analisados mostram na atualidade (Little, 2002, p. 23, apud Costa Filho, 2010, p 4).

Vale ressaltar que esta categoria engloba uma enorme diversidade de povos e comunidades, cuja amálgama, por assim dizer, é decorrente da luta política e da defesa dos seus territórios, no seio dos quais são evidenciados os elementos comuns dessa diversidade e não supostos "laços primordiais" que os ligam a uma mesma "tradição" (Costa Filho, 2010, p. 5). Como afirma Almeida,

A heterogeneidade aponta para diferenciações sociais, econômicas e religiosas entre esses povos, embora eles estejam em alguma medida unidos por critérios político organizativos e por modalidades diferenciadas de uso comum dos recursos naturais. O consenso que envolve o termo "tradicional" está sendo, portanto, construído a partir destes dissensos sucessivos, que aparentemente não cessam de existir (Almeida, 2007, p. 15-16).
Para o autor, não são heterogêneas apenas as identidades de grupos como povos indígenas, quilombolas, ciganos, pomeranos, afro-religiosos, ribeirinhos, quebradeiras de coco babaçu, seringueiros, pescadores artesanais, caiçaras, castanheiros e povos dos faxinais, dos gerais e dos fundos de pasto, dentre outros, mas "também os critérios que [os] agrupam e mobilizam" (Almeida, 2007, p. 15).

Percebe-se aqui o porquê das controvérsias que essa categoria suscita entre estudiosos, em função das suas possíveis ambiguidades. Por um lado, a mesma vem sendo ferramenta de luta para reduzir as disparidades entre estes povos e os demais cidadãos brasileiros, as quais são determinadas pela invisibilidade em que se encontram, assim como pelas pressões econômicas, fundiárias e de todo tipo de exclusão a que são submetidos. Do ponto de vista das disputas em torno das concepções de "desenvolvimento", esta luta tem um significado político e estratégico decisivo, uma vez que boa parte dos conflitos ambientais no Brasil está associada à invasão de seus territórios e comprometimento das suas comunidades. Para Zhouri (2016), os povos e comunidades tradicionais, ao abraçarem a defesa dos seus lugares, que é o locus das suas vivências, da sua história, do seu enraizamento, estão abraçando, também, "a procura por autodeterminação, a fuga aos movimentos hegemônicos do capital e a reapropriação da capacidade de definir seu próprio destino" (Zhouri, 2016, p. 15). Para a autora, que por sua vez evoca o trabalho de Massey (2000), contrariamente ao entendimento que imperava nos anos 90, o lugar já não deve ser visto como "uma categoria residual - o reino do arcaico, das tradições, o locus da a-historicidade - em que não existiria mudança social" (Zhouri, 2016, p. 14). Pelo contrário, a luta destes povos, 
[...] remete ao poder das pessoas optarem por permanecerem no lugar, ressignificando-o e transformando-o continuamente, como atestam várias lutas contra o avanço das barragens, das mineradoras, das monoculturas do agrodiesel, enfim, as formas industriais de ocupação do espaço para o capital, mercadoria a ser incorporada nos fluxos globais em detrimento dos sentidos diversos dos lugares. Muitos dos processos de territorialização em curso hoje - de quilombolas, indígenas, vazanteiros, geraizeiros - são processos de luta pelo significado e pela apropriação sociodiversa do meio ambiente contra a apropriação global feita pelo capital, que transforma territórios sociais, de acordo com Little (2002), em espaços abstratos, ou seja, lugares em espaços que contêm recursos naturais para a exploração capitalista (Zhouri, 2016, p. 15).

Não obstante isso, a categoria povos e comunidades tradicionais pode ter implicações homogeneizadoras. Essa ambiguidade, embora não retire seu mérito político, é reconhecida por pesquisadores que realizam essa mediação entre a ciência e a luta social. Nas palavras de Costa Filho (2010, p. 5, colchetes do autor), essa categoria,

Ao mesmo tempo em que denota um comprometimento maior do Estado ao assumir a diversidade no trato com a realidade social brasileira, pode ser associada acadêmica, política e tecnicamente a outras leituras homogeneizadoras como "pequenos produtores", "sitiantes", "posseiros", "agregados" e, mais recentemente "agricultores familiares", resultando na invisibilização de identidades ou atributos "étnicos". Esta perspectiva de obliteração de diferenças permanece latente na categoria atual [povos e comunidades tradicionais], ainda que afirme um processo semelhante para todos os grupos sociais historicamente excluídos e considerados como tais e resulte em ações reparativas por parte do Estado...
Também, ao resgatarmos e apreciarmos os usos e as valorações que estes grupos têm da natureza, há de se precaver neste estudo de usos essencialistas da denominação, especialmente os que possam implicar num viés do tipo "bom selvagem" ou de entendimentos de que estaríamos diante de culturas naturalmente "harmoniosas" com a natureza.

Nada mais longe disto na argumentação que pretendo desenvolver aqui. Entendo que a característica desses grupos que resultam no uso da natureza a que nos referimos está relacionada à sua condição material de realizar suas necessidades econômicas e simbólicas em interação direta com a natureza e a sua predisposição política identitária de preservar seus modos de vida, por encontrarem eles preferíveis aos modos de vida típicos urbano-industriais, nos quais, por outra parte, ver-se-iam subalternizados, discriminados, desterritorializados, perdendo os laços comunitários e as ligações de ancestralidade. Como bem lembram Danowski \& Viveiros de Castro (2014, p. 38),

\begin{abstract}
A concepção positiva de wilderness como "mundo sem nós" esteve no centro de alguns movimentos ambientalistas contemporâneos, como o preservacionismo radical, que teve sua atuação mais expressiva na segunda metade do século XX. Essa vertente do ambientalismo considera a existência de seres humanos como essencialmente desnaturante, não hesitando portanto em propor a expulsão, para fora dos espaços "naturais" de toda e qualquer coletividade humana ali localizada (via de regra, povos indígenas ou populações ditas tradicionais, isto é, com fraca inserção no mercado capitalista).
\end{abstract}

Esta menção à Danowski \& Viveiros de Castro (2014) é oportuna por dois aspectos: por um lado, 
auxilia a se desvencilhar de qualquer resquício de ideia de que natureza natural é natureza sem gente. Essa ideia, além de ser inconsistente empírica e teoricamente, constitui uma ameaça à própria continuidade dos modos de vida dos povos e comunidades tradicionais cujos territórios se encontram em áreas preservadas, mesmo diante do fato de que eles próprios, muitas vezes, são os verdadeiros responsáveis de tal preservação?.

Por outro lado, chama a atenção, a expressão do autor ao mencionar os "povos indígenas ou populações ditas tradicionais, isto é, com fraca inserção no mercado capitalista" (grifos meus). Para além da sinalização de certa desconfiança por parte dos autores com relação à noção de Povos e Comunidades Tradicionais, interessa-me ressaltar a característica apontada como grupos que têm "fraca inserção no mercado capitalista".

Penso que essa característica, embora não seja descritiva dos atributos identitários, nem das especificidades culturais, históricas, genealógicas, territoriais e de visões e usos da natureza, conserva um traço estratégico de inteligibilidade que deve ser ressaltado. De fato, a fraca inserção no mercado capitalista se corresponde com uma racionalidade peculiar (ou, melhor dizendo, contrasta com a racionalidade monocultural e hegemônica) e critérios de valoração não redutíveis à lógica do mercado e da economia monetária. Mas, além disto, essas outras racionalidades se validam porque são justamente elas que permitem sustentar estratégias de autonomia, econômicas e culturais, que se contrapõem à subalternização que ocorre nos casos em que esses grupos são cooptados pelas cadeias de produção integradas à lógica capitalista, seja através da integração produtiva (geralmente por meio de monoculturas) seja através da migração aos centros urbanos (via de regra como força de trabalho de baixa qualificação).

Essas racionalidades a que nos referimos têm semelhanças com o que foi conhecido como "racionalidade camponesa" (Toledo, S/D) embora, nesse caso, esteja-se a falar de produtores muito diversificados, porém basicamente agricultores, e entre os povos e comunidades tradicionais encontremos outras variações aonde a agricultura, embora presente, não necessariamente é a atividade principal ou a que marca o maior traço identitário.

Na racionalidade camponesa, a fraca integração no mercado está associada a um uso múltiplo e diversificado dos elementos da natureza na forma de valores de uso. Conforme Toledo,

No contexto de racionalidade econômica com predomínio dos valores de uso, os camponeses estão obrigados a adotar uma estratégia que maximize a variedade de produtos produzidos para prover as necessidades da unidade camponesa, que conta com o alto grau de autossuficiência próprio das unidades camponesas de produção. Os camponeses manipulam a paisagem natural de modo a manter e aumentar duas características meio-ambientais: heterogeneidade espacial e diversidade biológica. Esta estratégia multiuso (Toledo e Col., 1976) permite aos camponeses fazer a gestão de diferentes unidades geográficas, com diferentes componentes bióticos e físicos. Os camponeses tentam evitar a especialização de seus espaços naturais e de suas atividades produtivas, um

\footnotetext{
${ }^{9}$ Mais ainda, está ocorrendo que compensações ambientais de obras ou empreendimentos de alto impacto ambiental acabam impulsionando a criação de parques sem gente. Assim, povos e comunidades tradicionais são "cercados" (Anaya, 2012) tanto pelos empreendimentos capitalistas de alto impacto, quanto pelas compensações ambientais que esses mesmos empreendimentos financiam, numa lógica duplamente perversa, que encontra amparo na ideia de wilderness e natureza natural sem gente.
} 
traço intrinsecamente contraditório com as tendências predominantes na maioria dos projetos de modernização rural (Toledo, S/D, p. 5, tradução minha) ${ }^{10}$.

No entanto, embora defendo que a fraca integração ao mercado é de fato uma característica fundamental, não me parece que descrever suas valorações apenas como "valores de uso" seja satisfatório. Falarmos apenas na ideia de valores de uso, ainda que enfatize-se a distinção com relação ao "valor de troca" típico da racionalidade capitalista, da qual povos e comunidades tradicionais passam longe, reduz as valorações a uma relação meramente instrumental, o que me parece não corresponder com a realidade.

Em termos éticos, não obstante haja uma diversidade de concepções de valoração definidas pelos diversos autores da ética ambiental ocidental, tudo gira em torno de uma distinção crucial, que é a que estabelece a oposição entre valor instrumental e outras formas de valoração. A racionalidade hegemônica naturalizada não nega essa oposição. $\mathrm{O}$ que há, isto sim, é a disputa em torno de aonde deve se estabelecer a fronteira entre o instrumental e o não instrumental. Contudo, é essa mesma distinção dualista que permite a moralização seletiva da natureza, muitas vezes imbuída das arbitrariedades que se explicam, sobretudo, pelas relações de poder. $\mathrm{O}$ caso mais evidente é o da indústria pet e da indústria da carne. Por que os porcos não mereceriam a mes- ma afeição que cães e gatos? Menos reconhecido é o caso da "natureza natural", isto é, sem gente, e a natureza antropizada de áreas urbanas e rurais. Por que dizer que o problema radica na presença ou não de gente se foi "gente" que a conservou em estado "natural"? Trata-se de formatações dualistas, estabelecidas na forma de termos opostos e mutuamente excludentes, cujas fronteiras são tão ambíguas e duvidosas quanto o são as fronteiras entre homem e animal e entre natureza e cultura.

Por isso, o problema ético no uso da natureza não consiste, no meu entender, no seu uso instrumental per se, mas nas formações valorativas em que o valor da natureza é apenas instrumental, isto é, nas quais todas as outras formas de valorar são sumariamente ignoradas. São estes os processos de coisificação, ou seja, de imposição à natureza (ou a partes dela, ou a seres vivos não humanos), de um estatuto ontológico no qual servir a propósitos humanos é a condição exclusiva do existir. Isto ocorre em formações valorativas que são tributárias da mesma territorialidade urbano-industrial-capitalista.

Para os povos e comunidades tradicionais, diferentemente, os usos da natureza e das paisagens implicam no reconhecimento de valores de uso, mas estes não são reconhecidos através de expurgar outros valores não instrumentais. Pelo contrário, valores de uso (instrumentais, porém não capitalistas) convivem com outros valores (não instrumentais, e também não capitalistas) que são parte importante

\footnotetext{
${ }^{10}$ En el contexto de la racionalidad económica con predominio de los valores de uso, los campesinos están obligados a adoptar una estrategia que maximice la variedad de productos producidos, para proveer las necesidades de la unidad campesina, que cuenta con el alto grado de autosuficiencia de las unidades campesinas de producción. Los campesinos manipulan el paisaje natural de tal forma que se mantienen y favorecen dos características medio-ambientales: heterogeneidad espacial y diversidad biológica. Esta estrategia multiuso (Toledo y Col., 1976) permite a los campesinos gestionar diferentes unidades geográficas, con diferentes componente bióticos y físicos. Los campesinos intentan evitar la especialización de sus espacios naturales y de sus actividades productivas, un rasgo intrínsecamente contradictorio con las tendencias predominantes de la mayoría de los proyecto de modernización rural (Toledo, S/D, p. 5).
} 
do sentido que eles dão aos seus modos de vida. Esses outros sentidos, paralelos e complementares aos valores de uso, implicam no reconhecimento simultâneo do que, em termos da ética ambiental acadêmica, poderia ser denominado como valores intrínsecos ou bens inerentes ${ }^{11}$, ou seja, valores cuja existência é reconhecida independentemente da importância deles para os humanos. Em outras palavras, para os povos e comunidades tradicionais, as valorações instrumentais não estão dissociadas de outras valorações.

Esta combinação sintética de valorações viabiliza um fenômeno extremamente relevante do ponto de vista da construção de moralidades ambientais. Para povos e comunidades tradicionais, o uso de entes que possuem, além dos atributos que tornam o seu uso conveniente, outros atributos de valor, confronta estes povos com os dilemas morais associados ao uso da natureza e de seres vivos não humanos e os leva a encontrar formas de processá-los, sem negá-los, mas reconhecendo-os. Com efeito, é justamente porque a natureza e os seres vivos não humanos não são vistos apenas pelo seu valor instrumental, isto é, de forma coisificada, que o uso deles se dá num contexto de dilema moral -É correto usar assim? É justificado matar?

A resposta a essas perguntas se dá no contexto do atendimento a necessidades vitais. Na medida em que o uso imaginado seja para o atendimento de necessidades vitais a resposta tenderá a ser, em geral, positiva. Outras conjecturas tenderão a ser descartadas. E, no contexto da resposta positiva, ou seja, do uso moralmente autorizado, haverá em geral algum tipo de ritualização desse processa- mento moral. Práticas comunitárias ou religiosas específicas e interdições cumprem também esse papel de ritualizar o processamento moral, ou seja, ritualizar o fato do uso da natureza ser algo sério, passível de ser aprovado, mas sob condições.

É justamente o confronto com os dilemas morais inevitáveis ao se usar a natureza que explica o desenvolvimento de uma eticidade que media e regula o uso da natureza. E é justamente esse confronto que é obliterado, através da valoração meramente instrumental que guia a lógica capitalista dominante nas populações completamente integradas ao mercado.

\section{Ontologias relacionais e algumas implicações}

Ao pensarmos na confrontação entre territorialidades, valorações da natureza e defesa dos lugares embaçada em cosmovisões não integradas à racionalidade urbana-industrial-capitalista nossa reflexão nos defronta com a proposição ambiciosa e provocativa da ontologia política de Arturo Escobar e outros como Blaser \& De La Cadena.

Para Escobar (2015), as lutas territoriais e a resistência de modos de vida que perduram em torno de valorações que não se rendem à redução meramente instrumental estão associadas a uma "resistência ontológica". Para o autor, a luta por estes territórios é uma luta contra a dinâmica do capital global e uma luta pela sua autonomia, mas, muitas vezes, não se limita a isso. Com efeito, esses dois aspectos da dimensão territorial estão corretos, diz ele, mas são insuficientes para explicar a totalidade

\footnotetext{
${ }^{11}$ Tomo esta expressão da perspectiva biocêntrica elaborada por Paul Taylor (Taylor, 2011). Uma contextualização desta discussão é encontrada em Florit (2016) e Kuhnen (2016).
} 
destes fenômenos e exprimir sua relevância. Assim define o autor sua tese,

A perseverança das comunidades e movimentos de base étnico-territorial envolvem resistência, oposição, defesa, e afirmação dos territórios, mas com frequência pode ser descrita de forma mais radical como ontológica. [...] Neste marco, o que 'ocupa' é o projeto moderno de Um Mundo, que busca converter aos muitos mundos existentes num só (o mundo do indivíduo e do mercado), e o que persevera é a afirmação de uma multiplicidade de mundos. Ao interromper o projeto globalizador neoliberal de construir Um Mundo, muitas comunidades indígenas, afrodescendentes e camponesas podem ser vistas como antecipando lutas ontológicas (Escobar, 2015, p. 92-93, tradução minha) ${ }^{12}$.

Para o autor, a ameaça sobre estes povos e seus territórios não é apenas uma ameaça econômica, mas uma ameaça a uma forma de existir. Essas formas de existir são ameaçadas pela "ontologia dualista" da modernidade - capitalista, liberal e secular -, que na América Latina adquire a forma do projeto desenvolvimentista. Esta ontologia dualista, "separa o humano e o não humano, natureza e cultura, indivíduo e comunidade, 'nós' e 'eles', mente e corpo, o secular e o sagrado, razão e emoção, etc.". A partir dela, "esta modernidade tem se atribuído o direito de ser 'o' Mundo (civilizado, livre, racional), à custa dos outros mundos existentes possíveis." (Escobar, 2015, p. 93). Como vimos, essa ontolo- gia dualista perdura, inclusive, no campo da ética ambiental, quando a distinção valor intrínseco e valor instrumental é considerada como a clivagem fundamental.

O que o autor quer dizer é que essa consolidação, pela imposição, de "Um Mundo" (que está chegando a sua expressão maior com a globalização neoliberal) vem erodindo sistematicamente a base ontológica-territorial dos grupos sociais que não se ajustam a ele, particularmente aqueles cujas concepções de mundo são não dualistas, ou seja, não se apoiam nas separações mencionadas. Escobar chama elas de "ontologias relacionais". Elas, nas palavras do autor, podem ser definidas "como aquelas em que nada (nem os humanos nem os não-humanos) preexiste às relações que os constitui. Todos existimos porque existe tudo" (Escobar, 2015, p. 93).

Há muitíssimas maneiras de expressar a relacionalidade. Um princípio chave é que a realidade está feita de entidades que não pré-existem às relações que as constituem. Talvez o budismo tenha a posição mais radical a este respeito ao afirmar que nada existe em si, mas tudo interexiste. Como explica o mestre Thich Nhat Hanh, uma flor não existe, interexiste (Escobar, 2012, p. 7, tradução minha) $)^{13}$

Nessa ontologia relacional, a existência dos seres, humanos e não humanos, resulta de condições específicas de interação, não contando com um

\footnotetext{
${ }^{12}$ La perseverancia de las comunidades y movimientos de base étnico-territorial involucran resistencia, oposición, defensa, y afrmación de los territorios, pero con frecuencia puede ser descrita de forma más radical como ontológica. [...] En este marco, lo que 'ocupa' es el proyecto moderno de Un Mundo que busca convertir a los muchos mundos existentes en uno solo (el mundo del individuo y el mercado); lo que persevera es la afrmación de una multiplicidad de mundos. Al interrumpir el proyecto globalizador neoliberal de construir Un Mundo, muchas comunidades indígenas, afrodescendientes, y campesinas pueden ser vistas como adelantando luchas ontológicas (Escobar, 2015, p. 92-93).

${ }^{13}$ Hay muchísimas formas de expresar la relacionalidad. Un principio clave es que la realidad está hecha de entidades que no pre-existen a las relaciones que las constituyen. Quizás el budismo tienen la posición más radical a este respecto al afirmar que nada existe en sí, todo interexiste; como explica el maestro Thich Nhat Hanh, una flor no existe, interexiste (Escobar, 2012, p. 7).
} 
estatuto ontológico separado. Para o autor, a ideia de "interexistência" remete à concepção budista tradicional em que a natureza dos objetos e dos seres não está dada pelo que aparentam ser, mas pela interdependência de fatores extrínsecos ${ }^{14}$.

Outra forma de se referir ao relacional mencionada por Escobar é a que faz referência à inexistência, em muitas sociedades não ocidentais, das divisões natureza-cultura e indivíduo-comunidade. Assim, sustenta, a relação entre o humano e o não humano seria contínua e formadora de um mundo aonde o humano e o natural se dão com base em outras distinções. De fato, diz ele, "não existe o "indivíduo", mas pessoas em contínua relação com todo o mundo humano e não humano ao longo dos tempos" (Escobar, 2012, p. 7) ${ }^{15}$.

Assim, segundo Escobar, a racionalidade apoiada na redução de uma entidade da natureza à condição de mero objeto por parte de um sujeito, não tem como acontecer. Isto porque,

Quando está a se falar de uma montanha, uma lagoa ou um rio, como um ancestral ou como uma entidade viva, está se referenciando a uma relação social, e não a uma relação de sujeito-objeto. Cada relação social com não humanos pode ter protocolos específicos, mas não são (ou não são só) relações instrumentais e de uso. Assim, o conceito de comunidade, em princípio, centrado nos humanos, expande-se para incluir a não humanos (que podem ir de montanhas a animais, passando por espíritos, dependendo dos territórios específicos) (Escobar, 2015, p. 97, tradução minha) ${ }^{16}$

E aí se coloca uma questão por demais desafiadora, pois, na política convencional,

[...] onde a oposição a um empreendimento de mineração em termos de "o morro não quer", somente pode ser aceita enquanto uma demanda cultural - "os indígenas têm direito a seu morro e suas crenças assim como outros têm direito à sua igreja e a seu Deus". Nestes termos, os "outros" [os indígenas] constituem-se em sócios menores nas coalizões que se opõem a um empreendimento de mineração. São bons para relações públicas e a mobilização, mas, em face à realpolitik, o que conta em última instância é a "realidade", sendo que esta é representada pela ciência (ou pelo menos pelo senso comum moderno que nos diz que um morro é nada mais do que uma formação rochosa) (Escobar, 2012, p. 8, itálicos do autor, tradução minha) ${ }^{17}$

\footnotetext{
${ }^{14}$ Esta ideia é assim explicada em outro lugar por Thich Nhat Hanh, o autor citado por Escobar: "Quando examinamos o coração de uma flor, vemos nele as nuvens, a luz do sol, os minerais, o tempo, a terra e todas as outras coisas que existem no universo [...] Com efeito, a flor é totalmente formada por elementos que lhe são extrínsecos; ela não possui uma existência independente e individual. Ela "interexiste" com todas as outras coisas do universo. [...] Quando percebemos a natureza da interexistência, as barreiras entre nós e os outros se dissolvem... (Thich Nhat Hanh, 1997, p. 32).

${ }^{15}$ Para Escobar, as figuras mais destacadas dessa antropologia ecológica e relacional são Marilyn Strathern, Tim Ingold, Philippe Descola e Eduardo Viveiros de Castro.

${ }^{16}$ Cuando se está hablando de la montaña, o una laguna o rio, como ancestro o como entidad viva, se está referenciando una relación social, no una relación de sujeto a objeto. Cada relación social con no-humanos puede tener sus protocolos específicos, pero no son (o no solo) relaciones instrumentales y de uso. Así, el concepto de comunidad, en principio centrado en los humanos, se expande para incluir a no-humanos (que pueden ir desde animales a montañas y pasando por espíritus, todo dependiendo de los territorios específicos) (Escobar, 2015, p. 97).

${ }^{17}[\ldots]$ donde la oposición a un emprendimiento minero en términos de «el cerro no lo quiere», puede solo ser aceptada como una demanda cultural - «los indígenas tienen derecho a su cerro y creencias como otros tienen derecho a su iglesia y su Dios». En estos términos, los «otros» [os indígenas] se constituyen en socios menores en las coaliciones que se oponen a un emprendimiento minero; son buenos para la relaciones públicas y la movilización pero, de cara a la realpolitik, lo que cuenta en última instancia es la «realidad», y a esta la representa la ciencia (o cuando menos el sentido común moderno que nos dice que el cerro es una formación rocosa y nada más) (Escobar, 2012, p. 8, itálicos do autor).
} 
Levar a sério a existência dessas diversas ontologias implica em questionar premissas fundacionais do ocidente racional moderno. Por isso, diz Escobar citando a Blaser, esse questionamento cria o campo da ontologia política que seria a saída para evitar a armadilha epistêmica da modernidade (Escobar, 2015).

De fato, quando esses povos se comunicam com agentes da sociedade envolvente, o que fazem é um esforço de tradução. Trata-se menos de comunicar sua visão das coisas, e mais de fazer entender como são as coisas (ou, pelo menos, aspectos ignorados das coisas). Mas esse esforço dilui-se nas instituições e linguagem da política representativa convencional, permitindo, quando muito, uma "solução negociada" sob premissas sempre impostas pelo estado (Zhouri \& Valencio, 2014). Nela, os dizeres não têm absolutamente valor equivalente, porque, como diz Escobar, o que as instituições do estado conseguem é, no máximo, ouvir o que os outros (os que não estão nem querem estar no capitalismo global) acham e sentem, mas nunca se questionam o que as coisas são. Para a definição do que as coisas são, o que é levado em conta pelas instituições da sociedade envolvente, inquestionavelmente, é o que resulta da ontologia dualista consagrada pelo mix científico-industrial. Como ressalta Blaser,

[...] os conflitos decorrentes desta classe particular de desentendimento vão além de lutas (interessadas de forma complexa) a respeito da primazia de diferentes perspectivas culturais sobre a natureza ou o mundo e de fato envolvem a em-atuação, estabilização e proteção contínua de mundos ou ontologias diferentes, porém conectadas assimetricamente (Blaser, 2009, p. 85 , minha tradução) ${ }^{18}$.

Mas para aquém da discussão da ontologia política propriamente dita, o que quero colocar aqui é uma hipótese bem mais modesta: a de que modos de vida que convivem, interagem e usam a natureza reconhecendo nela diversas valorações (obviamente, decorrentes de outras ontologias) são de enorme relevância, porque é justamente a simplificação para valorações apenas instrumentais que tem tornado moralmente aceitável a utilização irrestrita e ilimitada da natureza e os outros seres. Estas outras valorações constituem per se um posicionamento contra hegemônico com relação à territorialidade urbano-industrial-capitalista.

$\mathrm{O}$ argumento de que a superação da redução instrumental é um fator protetor importante da natureza e que, portanto, o grande obstáculo seria a sua instrumentalização radical, já estava presente na ética ambiental dos anos 1970 que absorveu substantivas contribuições e reflexões anteriores questionando o antropocentrismo.

Mas então o que há de novo na proposição trazida aqui? O que quero enfatizar agora é a compreensão clara de que essa discussão fundamental da consideração moral da natureza que supõe a superação do antropocentrismo não pode ser feita deixando de lado a análise do papel das relações de poder entre os grupos humanos no contexto das quais as relações com a natureza se estabelecem, e

\footnotetext{
18 “ $[\ldots]$ los conflictos que se generan de esta clase particular de desentendimiento van más allá de luchas (complejamente interesadas) sobre la primacía de diferentes perspectivas culturales sobre la naturaleza o el mundo y de hecho involucran la en-actuación, estabilización y protección continua de mundos u ontologías diferentes pero conectadas asimétricamente" (Blaser, 2009, p. 85).
} 
que essas relações de poder estão ancoradas na dimensão territorial. Em outras palavras, o necessário questionamento do antropocentrismo e a luta contra a redução instrumental não pode ser feita ignorando as iniquidades socioambientais.

Por isso, defendo que a ética socioambiental deve ser capaz de reunir as duas coisas: superação do antropocentrismo (especialmente do antropocentrismo tosco, aquele que se apoia numa visão exclusivamente instrumental) e superação de iniquidades ambientais. E a superação do antropocentrismo tosco deve ser vista associada com a superação das iniquidades ambientais que são produto de relações de poder entre seres humanos.

\section{Premissas de valoração em porta-vozes de PeCTS}

Os povos e comunidades tradicionais possuem moralidades que dialogam com os dilemas morais inevitáveis do uso direto da natureza para o uso humano. Para eles, no uso da natureza e dos seres, nem tudo é aceitável. As premissas dessas moralidades não consideram os seres humanos como portadores exclusivos de consideração moral, nem validam as consequências distributivas da lógica de mercado. Por um lado, não tratam a natureza como sendo uma coisa. Por outro, não aceitam do capitalismo globalizado sua colonização (invasão e subalternização).

Utilizarei, agora, palavras de quem considero, neste contexto, porta-vozes qualificados de povos e comunidades tradicionais. São porta-vozes na medida em que tentam explicar para a sociedade envolvente um tipo de realidade, e o fazem numa linguagem que essa possa entender. Essas palavras ilustram e desenvolvem perspectivas compatíveis com os enunciados discutidos nas seções anteriores. Através delas, tornar-se-á evidente como as conceituações gerais apresentadas sobre os povos e comunidades tradicionais podem ser levadas a um nível de perspectiva ética, identificando alguns elementos que também servem de mediação para a análise de casos concretos. Vou me valer de contribuições de Douglas Krenak, liderança do povo Krenak, e do antropólogo Eduardo Viveiros de Castro. No primeiro caso, estarei me apoiando em entrevista realizada por mim com Douglas num contexto aonde se debatia o desastre da Samarco sobre o Vale do Rio Doce (rio Watu para o povo Krenak) ${ }^{19}$. No segundo caso, estarei me apoiando em entrevista concedida por Viveiros de Castro e Déborah Danowski à jornalista Eliane Brum e publicada no Jornal El País, na sua edição em português (Brum, 2014). Ambas as falas se referem a perspectivas de povos indígenas. No caso de Douglas Krenak, à perspectiva de seu povo. No caso de Viveiros de Castro, à perspectiva indígena tratada em termos gerais. Muitas das considerações aqui apresentadas são aplicáveis, mutatis mutandis, a povos tradicionais não indígenas, como quilombolas, vazanteiros e geraizeiros.

Consideremos primeiramente, através de Douglas Krenak, a concepção ontológica com relação a componentes da natureza e da paisagem. Ao tentar explicar para um interlocutor não índio o que é a entidade por eles denominada de Watu, ele disse:

O nosso povo ele tem o rio [...], que as pessoas

\footnotetext{
${ }^{19}$ Trabalho de campo. Entrevista realizada em 03/05/2016.
} 
conhecem como Rio Doce..., mas, no nosso povo ele é chamado de "Watu" que é "O Grande Rio" e ao longo de toda a nossa existência desde quando nosso povo veio ao mundo. [...] E ele está presente em todos os momentos de nossa vida... Então isso faz com que, em nós, é como se a gente estivesse integrado um com o outro. Nosso povo não se vê dissociado do Rio Doce, do meio ambiente... Sabe? Até porque o Rio Doce ele é uma entidade muito sagrada pro nosso povo... Nós dizemos que ele é parente porque, ele sempre nos alimentou, ele sempre nos protegeu com suas enchentes, com suas ilhas. [...] E ele sempre nos deu refúgio. Então a gente fala que ele é nosso parente porque ele foi nossa mãe, foi nosso pai e foi nosso irmão. Ele foi mãe, porque ele sempre deu de comer pra nós, ele sempre nos alimentou. Ele foi pai porque ele sempre nos refugiou, quando a gente ia buscar reforço das guerras a gente entrava no rio, a gente nadava do outro lado, a gente se escondia em suas águas, em suas cachoeiras, nas suas corredeiras... pra não ser... exterminados pelos brancos. E ele é um irmão tão presente pra nós, porque é nele que a gente partilha alegria, lazer, é nele que a gente deposita confiança de ensinar o nosso filho a nadar, de ensinar o nosso filho a pescar, a caçar, a cuidar dele. Isso é irmandade. Então ele é nosso irmão. Então não tem como a gente dizer que o Rio Doce é uma água que corre ali, separado da nossa vida. Ele é muito especial. Ele é muito sagrado pra nós. [...] E ele é cura! Ele é cura pra nós. Nós temos rituais sagrados com ele, que nós aprendemos desde muito antigamente com os nossos ancestrais... e é ele que leva toda a impureza... embora... toda a coisa ruim do nosso povo. Nós temos um respeito muito grande por ele, é uma das entidades mais sagradas que o nosso povo tem e que hoje, ele se encontra da forma que está. Morto! Sem vida! E... e isso tem prejudicado muito. Porque nós ficamos diante... de uma cena... que eu acho que nós nunca vamos esquecer. [...] Isso é muito sagrado. Isso pra nós é primordial. [...] Você ter o contato com essas águas, de você poder entrar nessas águas e de saber o que essas águas faz com teu corpo, com a tua alma... isso é uma coisa que não tem como você dizer que o rio é uma coisa e nós somos outra. Ele é presente demais na nossa vida. [...] Do simples fato da gente achar que o outro é semelhante, de que o rio é algo ou alguém, [...]. Ai a gente começa a ter um certo tipo de respeito entre nós, e entre a mãe natureza que nós somos parte (Douglas Krenak, 2016).

Douglas se refere ao rio como um "parente"20, alguém com quem se tem uma total interdependência, e de quem é difícil se dizer que haja uma separação nítida entre "eu" e "outro". Além disso, ele é alguém crucial do ponto de vista das necessidades vitais, mas que agora está morto, ou quase morto, sem espírito, e que precisa descansar para, talvez, conseguir se recuperar.

Esses enunciados não deixam muita dúvida de que Douglas Krenak aderiria a uma perspectiva do tipo dos direitos da natureza, conforme a que tem sido consagrada na constituição do Equador graças a luta dos povos indígenas (Acosta \& Martínez, 2011). Ela lhe permitiria pleitear o direito do Watu a ser reparado até restabelecer sua condição original, uma vez que concebe a Natureza como sujeito de direito. Trata-se de uma equiparação com os seres humanos que, embora ainda cause certa estranheza entre juristas ocidentais, seria aceitável com a maior naturalidade por quem, como Douglas Krenak, concebe o rio como seu parente. No entanto, a própria concepção de uma entidade separada que possa ser considerada como um sujeito independente é colocada em questão. Parafraseando as palavras de Escobar, o rio e os Krenak existem porque existem

\footnotetext{
${ }^{20}$ Essa expressão tem sido muito usada pelo povo Krenak para tentar explicar para a sociedade envolvente o que o rio, atingido pelo desastre da Samarco, significa para eles denotando identidade, laço de sangue, etc.
} 
as relações que os constitui. Todos existem porque existe tudo.

Na sua perspectiva, ainda, existe um "tratado" com a mãe natureza que teria sido quebrado pelos seres humanos. Este tratado estabeleceria que há limites para o uso da natureza, e que este limite estaria no atendimento de necessidades vitais. Nas palavras de Douglas Krenak,

A mãe terra... ela nos deu o direito de explorar ela pra sobrevivência. É isso que o meu povo entende... Você tem o direito de explorar a natureza, a mãe natureza, pra você sobreviver. Isso ela permite. E esse foi o tratado... Agora pra você poder acumular riqueza, pra você poder... dominar... [...], tentar exterminar... outras coisas que não foi você que criou, isso ela não suporta. Isso ela não aceita... É só a gente perceber o que tá acontecendo em volta que a gente vai perceber que ela não suporta e ela dá a resposta dela. E ai ela não distingue raça, cor, gênero... Ela não quer saber se foi eu ou você que fez o mal. Ela é imparcial... [...]. Não fomos nós (os Krenak) que poluímos o rio, mas ela não quer saber... [...]. Então hoje nós estamos sem caça, sem pesca... Ela poderia muito bem voltar com isso, ela tem esse poder... mas ela tem que... demonstrar a força dela também, ela tem que mostrar o que estão fazendo, que é errado, né? Porque o tratado é: "Vocês podem viver, aqui!" Então vocês têm a permissão de explorar pra sobreviver... nada mais do que isso. Só que a gente descumpriu o trato [...] (Douglas Krenak, 2016).

Ao ser questionado sobre a relação com os animais na caça, a ponderação dele foi a seguinte:

Nós tentamos utilizar tudo que a gente retira da natureza. Quando você caça... a capivara... quando você caça algum tipo de animal, você aproveita ao máximo ele... [...] pra o que vocêfez não surtir tanto efeito. Então quando você caça a capivara, além da carne dela, você retira um óleo, que é... pra medicina tradicional, [...]. Quando você caça um animal, como ele caçou [se referindo a um parente que o acompanhava que portava uma bolsa de pele], a pele serve pra fazer uma bolsa, [...] Então... é... isso é uma forma da gente poder demonstrar que a gente não quer destruir só, a gente quer aproveitar, a gente quer... recompor (Douglas Krenak, 2016).

Já ao ser indagado pelo processo da mineração, do qual ele e seu povo são vítimas diretas, sua consideração foi que

[...] a mineração, pra mim é isso ai que a gente tá vendo, [...]. É... a destruição de fato, porque ela é...é muito rápido. Ela... a mineração pega um morro dessa magnitude aqui, e com menos de dois anos... você vê um morro inteiro que demorou anos e anos pra se formar, ele vira barro. Isso é uma preocupação que nós temos assim, porque... e é acelerado o processo dessa destruição e o... o impacto disso também é rápido, [...]. Então a mineração pra nós é uma destruição rápida de tudo (Douglas Krenak, 2016).

O "tratado" expressa o critério de permissibilidade conferido para o atendimento de necessidades vitais, associado a um aproveitamento minucioso, e aos limites a essa utilização, dados pela suficiência no atendimento a tais necessidades. As mesmas, como diria Max-Neff et al. (2001), não são infinitas, e exatamente por isso servem como referência de permissão. A exploração para a acumulação é, por definição, sem limites, e leva a processos como a mineração que ao deslocar o sentido das necessidades vitais para o da acumulação, viola também o critério temporal da recomposição da natureza e, portanto, de aniquilação do território. Um morro de constituição milenar é devastado em poucos anos. 
Eduardo Viveiros de Castro expressa essa relação diferenciada que os índios têm com os dilemas morais decorrentes do uso da natureza para a atenção de necessidades vitais do seguinte modo,

Uma coisa é você dizer que os animais são humanos, no sentido de direitos humanos. Outra coisa é dizer que os animais são pessoas, isto é, são seres que têm valor intrínseco. É isso o que significa ser pessoa. Reconhecer direitos aos demais viventes não é reconhecer direitos humanos aos demais viventes. É reconhecer direitos característicos e próprios daquelas diferentes formas de vida. Os direitos de uma árvore não são os mesmos direitos de um cidadão brasileiro da espécie homo sapiens. O que não quer dizer, entretanto, que ela não tenha direitos. Por exemplo, o direito à existência, que só pode ser negado sob condições que exigem reflexão. Os índios não acham que as árvores são iguais a eles. O que eles acham simplesmente é que você não faz nada impunemente. Todo ser vivo, com exceção dos vegetais, tem que tirar a vida de um outro ser vivo para sobreviver. A diferença está no fato de que os índios sabem disso. E sabem que isso é algo sério. Nós estamos acostumados a fazer a nossa caça nos supermercados, não somos mais capazes de olhar de frente uma galinha antes de matála para comer. Assim, perdemos a consciência de que nós vivemos num mundo em que viver é perigoso e traz consequências. E que comer tem consequências. Os animais seriam pessoas no sentido de que eles possuem valor intrínseco, eles têm direito à vida, e só podemos tirar a vida deles quando a nossa vida depende disso. Isso é uma coisa que, para os índios, é absolutamente claro. Se você matar à toa, você vai ter problemas (Brum, 2014, p. 18-19).

Essa interpretação de Viveiros de Castro é especialmente relevante na nossa argumentação. Ele explica como funcionam certos critérios de valor entre os índios, e, por extensão, com outros povos e comunidades tradicionais, mas o faz utilizando uma linguagem que também dialoga com a ética ambiental ocidental. Traduzindo nos termos enunciados acima, poder-se-ia dizer que, para os índios, animais e plantas são portadores de um bem inerente, só que esse reconhecimento não é feito num contexto deontológico, de regras morais absolutas, mas situado num contexto aonde a realização de necessidades vitais se faz em interação direta com a natureza e seres vivos não humanos. Haveria algo assim como um biocentrismo situado num modo de vida específico, aonde seres vivos humanos e não humanos interagem, não sem conflito, para realizar suas necessidades. Em se tratando de necessidades vitais, no conflito estaria autorizado matar, sendo que não seria esse o caso em outras circunstâncias.

A situalidade, quero dizer, o caráter de ser situado, é crucial não apenas como justificativa para a ação. Ela é crucial, também, porque é nela que se dá a experiência do agente que é processada eticamente. É nessa situalidade que se manifestam, na consciência do agente, os dilemas morais, os conflitos entre valores contraditórios, entre afeições e interesses, entre ele e a alteridade. Voltando às palavras de Viveiros de Castro na entrevista à Eliane Brum,

[...] o índio que vai para o mato e tem que flechar o inimigo, ele tem que arcar com as consequências psicológicas, morais, simbólicas disso. Aquele soldadinho americano que está num quartel nos Estados Unidos, apertando um botão, ele nem sabe o que está fazendo. Porque ele está longe. Você cada vez mais distancia os efeitos das suas ações de você mesmo. Então nós somos todos drones nesse sentido. A gente compra carne no supermercado quadradinha, bem embaladinha, refrigeradinha, sem cara de bicho. E você está o mais longe possível daquela coisa horrorosa que é o matadouro. Daquela coisa horrorosa que são 
as fazendas em que as galinhas estão enfiadas em gaiolas apertadas. Se o pessoal lembrar que 50\% das galinhas que nascem são galos e que esses $50 \%$ que nascem são triturados ao nascer para virar ração animal porque não colocam ovos, talvez não conseguissem comer galinhas. Se você mostrasse que metade dos pintinhos vão todos vivos para uma máquina que tritura, talvez melhorasse um pouco. Mas as pessoas não querem saber disso. Nisso, nós somos iguaizinhos ao soldado americano que aperta o botão para matar inocentes no Paquistão. Nós fazemos a mesma coisa com as galinhas. Nós somos todos drones (Brum, 2014, p. 19).

O contraste marcado aqui por Viveiros de Castro entre a moralidade indígena e a moralidade urbana através da metáfora dos drones é também rica e instigante. Ela nos ajuda a encontrar uma demonstração plausível para a explicação da gênese de moralidades ambientais contrastantes e incompatíveis. Essa explicação se dá pela situalidade da experiência, como foi definido acima.

Além disso, essa metáfora nos ajuda a ver como de fato são contrastantes e incompativeis essas duas moralidades, mesmo que pratiquem um tipo de ação aparentemente semelhante, como é o de se alimentar de animais. Os diversos modos de vida propiciam ou obliteram experiências que confrontam com os dilemas morais inevitáveis na relação com a natureza e os seres vivos não humanos. Independentemente dos sistemas simbólicos e teóricos utilizados para processar moralmente as experiências, só é possivel de ser processada a experiência que de fato aparece na consciência do agente moral.

Mas é preciso mais uma consideração, examinando a relação entre o confronto/obliteração da experiência e a territorialidade. Pois, se nos povos e comunidades tradicionais tem-se uma territorialidade na qual as consequências das suas ações ficam circunscritas aos seus lugares, isto é, nos territórios de fato percebidos e vivenciados e com os quais há ligações afetivas, no caso da territorialidade urbana-capitalista acontece algo muito diferente, pois os efeitos extrapolam, e muito, os lugares e a percepção territorial dos agentes. Com efeito, a vida da imensa maioria dos cidadãos urbanos transcorre desenvolvendo apegos aos seus lugares, mas com pouca noção das consequências ambientais concretas de seu modo de vida, o que significa dizer que ignora a territorialidade de seu próprio modo de vida. Em outras palavras, enquanto nos modos de vida de povos e comunidades tradicionais o lugar e a territorialidade tendem a ser sobrepostos e coincidentes num mesmo espaço, no modo de vida urbano-capitalista o lugar é apenas uma pequena parcela da sua territorialidade. E entre o bairro dos afetos e o território da pegada ecológica há uma distância que não entra de fato na experiência cotidiana dos agentes morais. É por isso que, conforme nos fala Viveiros de Castro, os agentes urbanos (de supermercado) são como soldados acionando drones. Sua experiência transcorre num lugar, mas as consequências em outro. A obliteração das consequências na experiência tem também uma dimensão espacial.

\section{Considerações finais}

A discussão da consideração moral da natureza que permite confrontar as posições antropocêntricas mais insustentáveis é uma contribuição inegável da ética ambiental. Não entanto, isto não pode ser feito deixando de lado a análise do papel das relações de 
poder entre os grupos humanos, no contexto das quais as relações com a natureza se estabelecem.

Essas relações de poder estão ancoradas na dimensão territorial. Por isso, o necessário questionamento do antropocentrismo e a luta contra a redução instrumental da natureza não pode ser feita ignorando as iniquidades socioambientais. Este seria, como aqui foi argumentado, o cerne da ética socioambiental.

Povos tradicionais têm premissas de valoração fundamentais para se pensar isto, na medida em que consideram limites morais aos usos da natureza e os seres vivos não humanos e, ao mesmo tempo, encarnam lutas no sentido de equidade ambiental. Por sua vez, as suas valorações constituem per se posicionamentos contra hegemônicos com relação à territorialidade urbano-industrial-capitalista.

Essas premissas estão associadas à sua territorialidade, assim como a instrumentalização radical dos seres não humanos, típica da sociedade urbano-industrial-capitalista, reproduz-se apoiada na obliteração espacial dos dilemas morais. Isto decorre de que a defesa da natureza, do rio, da mata, dos animais, realizada por estes povos não é apenas a defesa de um ambiente produtivo, mas também a defesa de algo a que se reconhece consideração moral.

Em muitos casos, esses povos se aproximam ao que se poderia chamar de biocentrismo situado num modo de vida específico, aonde todos os seres têm um valor inerente, embora isto não impeça seu uso quando associado ao atendimento de necessidades vitais. O caráter de ser situado é crucial justamente porque é nessa situalidade que se dá a experiência do agente que é processada eticamente. É nessa situalidade que se manifestam, na consciência do agente, os dilemas morais, os conflitos entre valores contraditórios, entre afeições e interesses, entre ele e a alteridade.

As lutas territoriais desses povos implicam numa ontologia diferenciada, não dualista, da qual surgem valorações incomensuráveis do ponto de vista da sociedade envolvente. A saída (para os povos, e também para a sociedade envolvente) é reconhecer estas concepções e as valorações associadas, para o qual é mister o reconhecimento de seus direitos territoriais. Isso oferecerá exemplos de uso da natureza associado à sua consideração moral, o que constitui uma contribuição imensa no sentido de produzirmos uma ética socioambiental satisfatória, do ponto de vista dos interesses da natureza e dos seres não humanos, e do ponto de vista da equidade ambiental.

\section{Agradecimentos}

Agradeço os comentários e sugestões recebidos em seminário, conversas informais e encontros de supervisão mantidas no GESTA-UFMG, nos quais uma versão preliminar desse texto foi apresentada, e aos/às avaliadores/as anônimos/as que contribuíram com sua leitura atenta e suas impressões. Também agradeço a leitura e sugestões de Diego da Silva Grava relativas ao manuscrito original e à Maria Roseli Rossi Avila pela revisão. Agradeço ainda ao Luis Carlos Avila Júnior pela transcrição da entrevista. Agradeço especialmente a Douglas Krenak pela entrevista concedida.

\section{Referências}

Acosta, A.; Martínez, E. (Org.). La Naturaleza con Derechos. Quito: Ediciones Abya Yala y Universidad Polítecnica 
Salesiana, 2011.

Almeida, A. W. B. de. Apresentação. In: Shiraishi Neto, J. (Org.). Direito dos povos e das comunidades tradicionais do Brasil: declarações, convenções internacionais e dispositivos jurídicos definidores de uma política nacional. Manaus: UEA, p. 9-18, 2007.

Anaya, F. C. De encurralados pelos parques a vazanteiros em movimento: as reivindicações territoriais das comunidades vazanteiras de Pau Preto, Pau de Légua e Quilombo da Lapinha no campo ambiental. Belo Horizonte, Tese (Doutorado em Sociologia), 2012.

Blaser, M. La Ontologia Política de um Programa de Caza Sustentable. In World Anthropologies Network (WAN) Red de Antropologías del Mundo (RAM). Electronic Journal, 4, 81-108, 2009.

Brasil. Decreto presidencial 6.040 de 7 de fevereiro de 2007. Institui a Política Nacional de Desenvolvimento Sustentável dos Povos e Comunidades Tradicionais. Brasília: DOU de $8 / 2 / 2007$.

Brum, E. Diálogos sobre o fim do mundo. Entrevista com Eduardo Viveiros de Castro e Déborah Danowski. Diário El País, Edição Brasil, 2014. Disponível em: $<$ http://brasil.elpais.com/brasil/2014/09/29/opinion/1412000283_365191. html>. Acesso em: 28 Jul. 2019.

Callicott, J. B. The Land Ethic. In: Jamieson, D. A companion to environmental philosophy. Malden: Blackwell Publishers, p. 204-217, 2001.

Costa Filho, A. Quilombos e Povos Tradicionais. Texto analítico do Mapa dos Conflitos Ambientais, GESTA, UFMG, 2010. Disponível em: http://conflitosambientaismg.lcc. ufmg.br/wp-content/uploads/2014/04/TAMC-COSTA_FILHO_Aderval_Quilombos_e_Povos_Tradicionais.pdf

Danowski, D.; Viveiros de Castro, E. Há um mundo por vir? Ensaio sobre os medos e os fins. Desterro: Cultura e Barbárie e Instituto Socioambiental, 2014.

Diegues, A. C. Sant'Ana. O mito da natureza intocada. São Paulo: Hucitec. 1996.

Elliot, R. La ética ambiental. In: Singer, P. (Ed.). Compêndio de ética. Madrid: Alianza Editorial, p. 391-404, 2004.
Escobar, A. Cultura y diferencia: la ontología política del campo de Cultura y Desarrollo. Revista Walekeru, 2, 8-29, 2012. Disponível em: http://edu-library.com/es/walekeru.

Escobar, A. Territorios de diferencia: la ontología política de los "derechos al territorio". Revista Desenvolvimento e Meio Ambiente, 35, 89-100, 2015. doi: 10.5380/dma.v35i0.43541

Felipe, S. Ética biocêntrica: tentativa de superação do antropocentrismo e sencientismo éticos.Ethic@-An international Journal for Moral Philosophy, 7(3), 1-7, 2012. doi: $10.5007 / 1677-2954.2008 \mathrm{v} 7 \mathrm{n} 3 \mathrm{p} 1$

Florit, L. F. Conflitos ambientais, desenvolvimento no território e conflitos de valoração: considerações para uma ética ambiental com equidade social. Desenvolvimento e Meio Ambiente, 36, 255-271, 2016. doi: 10.5380/dma. v36i0.41624

Florit, L. F. Ética ambiental ocidental e os direitos da natureza. Contribuições e limites para uma ética socioambiental na América Latina. Revista Pensamiento Actual, 17, 121-136, 2017. doi: 10.15517/pa.v17i28.29550

Florit, L. F.; Grava, D. da S. Ética ambiental e desenvolvimento territorial sustentável: uma análise com base na categoria de especismo. Ambiente \& Sociedade, 19, 23-42, 2016. doi: 10.1590/1809-4422asoc135333v1942016

Florit, L. F.; Sampaio, C. A.; Philippi Jr, A. Os desafios da ética socioambiental. In: Florit, L. F.; Sampaio, C. A. C.; Philippi Jr., A. (Org.). Ética Socioambiental. Barueri/SP: Manole, p. 3-16, 2019.

Florit, L.; Sbardelati, C.; Grava, D. Questão animal e território: um problema de ética socioambiental. In: Florit, L. F.; Sampaio, C. A.; Philippi Jr, A.. (Eds.). Ética Socioambiental. Barueri: Editora Manole, p. 261-290, 2019.

Funtowicz, S.O; Ravetz, J.R. The worth of a songbird: ecological economics as a post-normal science. Ecological Economics, 10, 197-207, 1994.

Hitlin, S. Os Contornos e o Entorno da Nova Sociologia da Moral. Sociologias, 17(39), 26-58, 2015. doi: 10.1590/15174522-017003902

Kuhnen, T. A. É possível ir além dos animais sencientes na definição dos limites da comunidade moral? Argumentos ecocêntricos, e a resposta biocêntrica na bioética ambiental. 
In: Rouanet, L.; Carvalho, M. (Orgs.). Ética e direitos dos animais. Florianópolis, EdUFSC, p. 181-220, 2016.

Laschefski, K. Licenciamento e equidade ambiental. As racionalidades distintas de apropriação do ambiente por grupos subalternos. In: Zhouri, A. (Org.). As tensões do lugar. Hidrelétricas, sujeitos e licenciamento ambiental. Belo Horizonte: Editora UFMG, p. 21-59, 2011

Little, P. E. "Territórios sociais e povos tradicionais no Brasil: por uma antropologia da territorialidade". Série Antropologia. N 322. Brasília: DAN/UnB. 2002.

Martínez-Alier, J. O ecologismo dos pobres. São Paulo: Contexto, 2007.

Marzochi, S. F. Ética ambiental no Brasil: história, campo de estudos e militância: entrevista com Luciano Félix Florit. Contemporânea, 8, 343-356, 2018. doi: 10.4322/23161329.063

Massey, D. Um sentido global de lugar. In: Arantes, A. A. (Org.). O espaço da diferença. Campinas: Papirus, p. 276-185, 2000.

Max-Neef, M.; Elizalde, A.; Hopenhayn, M. Desarrollo a escala humana. Montevideo: Nordan-Comunidad, 2001.

Pedro, A. P. Ética, moral, axiologia e valores: confusões e ambiguidades em torno de um conceito comum. Kriterion, 55(130), 483-498, 2014. doi: 10.1590/S0100$512 \times 2014000200002$

Rachels, J.; Rachels, S. Os elementos da filosofa da moral. Porto Alegre: AMGH, 7. ed., 2013.
Shiraishi Neto, J. (Org.). Direito dos povos e das comunidades tradicionais do Brasil: declarações, convenções internacionais e dispositivos jurídicos definidores de uma política nacional. Manaus: UEA, 2007.

Singer, P. [1994]. Ética prática. São Paulo: Martins Fontes, 2002 .

Taylor, P. W. Respect to Nature: A Teory of Environmental Ethics. Princeton University Press, 2011.

Thich Nhat Hanh. Vivendo Buda, Vivendo Cristo. Rocco, 1997.

Toledo, V. M. S/D. La Racionalidad Ecológica de la Producción Campesina. Revista Agroecología y Desarrollo, 5, S/D. Disponível em: http://www.clades.cl/revistas/5/ rev5art3.htm.

Varner, G. Sentientism. In: Jamieson, D. A companion to environmental philosophy. Malden: Blackwell Publishers, p. 192-203, 2001.

Zhouri, A. Povos Tradicionais, Meio Ambiente e Colonialidade. In: Paula, A. M. N. R. de; Anaya, F.; Ilde, M. H. de S.; Barbosa, R. S. (Orgs.). Povos e comunidades tradicionais: Contribuições para outro desenvolvimento. Montes Claros: Editora UNIMONTES, p. 9-19, 2016.

Zhouri, A.; Valencio, N. (Org.). Formas de matar, de morrer e de resistir: limites da resolução negociada de conflitos ambientais. Belo Horizonte: UFMG, 2014. 